\title{
The anthropometric status of schoolchildren in five countries in the Partnership for Child Development*
}

\author{
Partnership for Child Development $†$ \\ Scientific Coordinating Centre, Wellcome Trust Centre for the Epidemiology of Infectious Disease, Oxford University, \\ South Parks Road, Oxford OXI 3PS, UK
}

The success of child survival programmes and a growing population in the developing world have meant that more children than ever before are eligible to attend school. Although death rates may be low among school-age children, typically defined as aged between 5 and 15 years, this age-group experiences a considerable burden of disease, particularly from infections with parasitic worms (Warren et al. 1993). Treating parasitic worms has been shown to improve the growth, development, and cognitive functions of school-age children (Stephenson, 1987; Nokes \& Bundy, 1994), while anthropometric status, and heightfor-age in particular, have been found consistently to predict school performance (Jamison, 1986; Moock \& Leslie, 1986; Clarke et al. 1991). These studies indicate that programmes to improve the health and nutrition of school-age children may have an impact on their education as well as on their health.

The fact that children regularly assemble in one place, their school, provides an obvious opportunity to deliver health services through an existing infrastructure, and many of the treatments required by children, such as drugs to treat worm infections and micronutrient supplements, are inexpensive and simple to deliver, thus the potential costs of school health programmes are low. These apparent advantages were recognized by the World Bank (1993) in their World Development Report 1993 which identified school health programmes as one of five priorities for public health initiatives.

As a result of international interest in determining the usefulness of the school-based approach the Partnership for Child Development (PCD) was established in 1992 by a group of countries, donors and technical institutions to undertake operations research studies on the costs, benefits and processes of delivering a package of simple school health services and health education to children in schools, through the existing school system. Programmes typically involve both the Ministries of Health and Education in implementation, and national technical institutions in monitoring and evaluation (PCD, 1997a). The school health services currently being provided comprise periodic treatment for intestinal parasites, treatment for schistosomiasis where appropriate, and participatory health education. PCD programmes are typically being implemented in several districts so that, with experience, they can be expanded to more districts in each country, and so that the lessons learned can then be disseminated to other countries in the region.

In developing these programmes it soon became apparent that there was a lack of information on the health of school-age children, a dearth that contrasted notably with the extensive literature on children less than 5 years of age and the growing body of information on adolescents. The aim of the analysis presented here is to examine the anthropometric status of children enrolled in school in five countries of the Partnership for Child Development.

\section{Data and data analysis}

Data on anthropometric measurements for children enrolled in government schools were analysed from five countries: from primary and junior secondary school pupils in Ghana; from primary school children in Tanzania, Indonesia and India; and from primary and secondary school pupils in Vietnam. The schools were situated either in rural areas or around small towns. The data from Ghana (Volta Region), Tanzania (Tanga Region) and Indonesia (Central Java Province) were collected during rapid preliminary surveys to identify areas where PCD programmes could be implemented, monitored and evaluated. Additional data on children enrolled in school were obtained during specific research studies in Ghana of rural school-age children in Volta Region (PCD, 1995) and Eastern Region (Fentiman \& Hall, 1997), and for Tanzania from baseline surveys during studies of the impact of treating the parasitic infections of peri-urban schoolchildren in Tanga Region (Beasley, 1995). In India, data were obtained during an evaluation, sponsored by the PCD, of the addition since

\footnotetext{
* This paper was presented to the Nutrition Society on behalf of The Partnership for Child Development by Dr Andrew Hall, to whom correspondence should be addressed at the Scientific Coordinating Centre.

$\uparrow$ For full details of the Partnership for Child Development, see Appendix.

Abbreviations: NCHS, National Center for Health Statistics; PCD, Partnership for Child Development; RR, risk ratio; WHO, World Health Organization. Corresponding author: Dr A. Hall, fax +44 (0)1865 281245, email andrew.hall@zoo.ox.ac.uk
} 
1994 of health services to the Mid-Day Meals Programme of the State Government of Gujarat (Gopaldas \& Gujral, 1996). In Vietnam, data were collected as a part of anthropometric surveys undertaken by the National Institute of Nutrition in Ha Tay Province.

The data sets provided the age, sex, weight $(\mathrm{kg})$ and height $(\mathrm{m})$ of children. Table 1 shows the sample sizes by age and sex for each country. Age was only recorded to an accuracy of 1 year in Ghana and Tanzania, thus, the middle of the reported year of age was used when calculating anthropometric indices. In Indonesia, India and Vietnam the date of birth of children was known, so age to an accuracy of 1 month was used when calculating anthropometric indices. In Figs. 1, 2, 4, 6 and 8, data have been plotted for the mid-point of each year of age. The z-scores (see below) of height-for-age, weight-for-age and weightfor-height were calculated using Anthro Software (Sullivan \& Gorstein, 1990), which uses the National Center for Health Statistics (NCHS) reference values which are published in tabular form by the World Health Organization (WHO; 1983). Weight-for-height was only calculated for girls aged less than 10.0 years and for boys aged less than 11.5 years because of the adolescent growth spurt (Sullivan \& Gorstein, 1990). Body mass index (BMI) (weight $(\mathrm{kg})$ divided by height $\left(\mathrm{m}^{2}\right)$ ) was also calculated.

A $\mathrm{z}$-score is the value of a measurement expressed as the number of standard deviations the measurement lies from the mean value for a reference population; thus, in the context of anthropometry a boy aged 8.5 years with a $\mathrm{z}$ score of height-for-age of -2 is 2 SD shorter than the mean height of the sample of North American boys of the same age who comprise the NCHS reference population. Since anthropometric measurements typically show a Gaussian or normal distribution, only $2.3 \%$ of the NCHS population have anthropometric measurements less than 2 SD below the NCHS mean, and this value is typically used as a cutoff point to classify children as showing evidence of protein-energy malnutrition (WHO, 1983). For the purposes of descriptive analysis, children were classified as stunted, underweight and wasted if $\mathrm{z}$-scores of height-forage, weight-for-age and weight-for-height respectively were less than 2 SD below the NCHS median, and severely stunted, severely underweight and severely wasted if $z-$ scores of height-for-age, weight-for-age and weight-for- height respectively were less than 3 SD below the NCHS median.

Differences between mean values were compared using Student's $t$ test and differences between proportions using Chi-square tests. Risk ratios (RR) with $95 \% \mathrm{CI}$ are given where appropriate.

\section{Height}

Fig. 1( $(\mathrm{a}$ and $\mathrm{b}$ ) shows the mean height of boys and girls by age in each of the five countries, with the NCHS median and -2 SD of the mean for comparison. For all countries, mean values were consistently closer to the $-2 \mathrm{SD}$ line. The relationship between age and weight was similar and is not shown.

On the assumption that cross-sectional data reflect patterns of longitudinal growth, the year-to-year difference in mean height $(\mathrm{m})$ between all children was calculated separately for boys and girls using the data from Vietnam, because data were available for children across the whole age-range and because sample sizes were the largest. This year-to-year height difference is shown in Fig. 2 with, for comparison, the same year-to-year difference in the height of boys and girls who are on the NCHS median (data from WHO, 1983). Fig. 2 shows that the mean year-to-year differences in height were approximately $65 \%$ of the NCHS median year-to-year differences until the age of about 11 years in girls and 14 years in boys, and that there was no clear adolescent growth spurt in either sex. However, both boys and girls in Vietnam continued to show gains in height into later adolescence than children on the median of the NCHS reference growth curves.

\section{Height-for-age}

Fig. 3 shows the prevalence of stunting in the samples of boys and girls studied in five countries, indicating the percentage of schoolchildren who were stunted (height-forage $z$-score $<-2 \mathrm{SD}$ ) and, within that percentage, the percentage who were severely stunted (height-for-age $\mathrm{z}$ score $<-3 \mathrm{SD}$ ). The percentage of schoolchildren who were in each of these categories was approximately the same for all five countries (between 48 and $56 \%$ were

Table 1. The number of schoolchildren measured in each of five countries in the Partnership for Child Development by year of age and sex

\begin{tabular}{|c|c|c|c|c|c|c|c|c|c|c|c|c|c|c|c|}
\hline \multirow[b]{2}{*}{ Age (years) } & \multicolumn{3}{|c|}{ Ghana } & \multicolumn{3}{|c|}{ Tanzania } & \multicolumn{3}{|c|}{ Indonesia } & \multicolumn{3}{|c|}{ Vietnam } & \multicolumn{3}{|c|}{ India } \\
\hline & Boys & Girls & Total & Boys & Girls & Total & Boys & Girls & Total & Boys & Girls & Total & Boys & Girls & Total \\
\hline 6 & 133 & 75 & 208 & & & & & & & 282 & 288 & 570 & 99 & 107 & 206 \\
\hline 7 & 137 & 91 & 228 & 20 & 26 & 46 & 20 & 25 & 45 & 288 & 258 & 546 & 149 & 148 & 297 \\
\hline 8 & 31 & 71 & 102 & 56 & 95 & 151 & 91 & 88 & 179 & 311 & 236 & 547 & 155 & 158 & 313 \\
\hline 9 & 42 & 51 & 93 & 82 & 111 & 193 & 210 & 200 & 410 & 272 & 266 & 538 & 163 & 168 & 331 \\
\hline 10 & 44 & 59 & 103 & 122 & 156 & 278 & 229 & 197 & 426 & 266 & 257 & 523 & 152 & 177 & 329 \\
\hline 11 & 36 & 38 & 74 & 117 & 100 & 217 & 150 & 131 & 281 & 285 & 300 & 585 & 164 & 177 & 341 \\
\hline 12 & 69 & 108 & 177 & 120 & 109 & 229 & 99 & 62 & 161 & 264 & 296 & 560 & 187 & 196 & 383 \\
\hline 13 & 84 & 103 & 187 & 88 & 91 & 179 & 33 & 15 & 48 & 258 & 283 & 541 & 151 & 191 & 342 \\
\hline 14 & 87 & 145 & 232 & 69 & 54 & 123 & & & & 248 & 270 & 518 & 103 & 113 & 216 \\
\hline 15 & 116 & 86 & 202 & 40 & 56 & 96 & & & & 286 & 251 & 537 & 69 & 39 & 108 \\
\hline 16 & 81 & 54 & 135 & 39 & 22 & 61 & & & & 248 & 256 & 504 & & & \\
\hline 17 & 50 & 26 & 75 & & & & & & & 216 & 206 & 422 & & & \\
\hline Total & 910 & 907 & 1817 & 753 & 820 & 1573 & 832 & 718 & 1550 & 3224 & 3167 & 6391 & 1392 & 1474 & 2866 \\
\hline
\end{tabular}



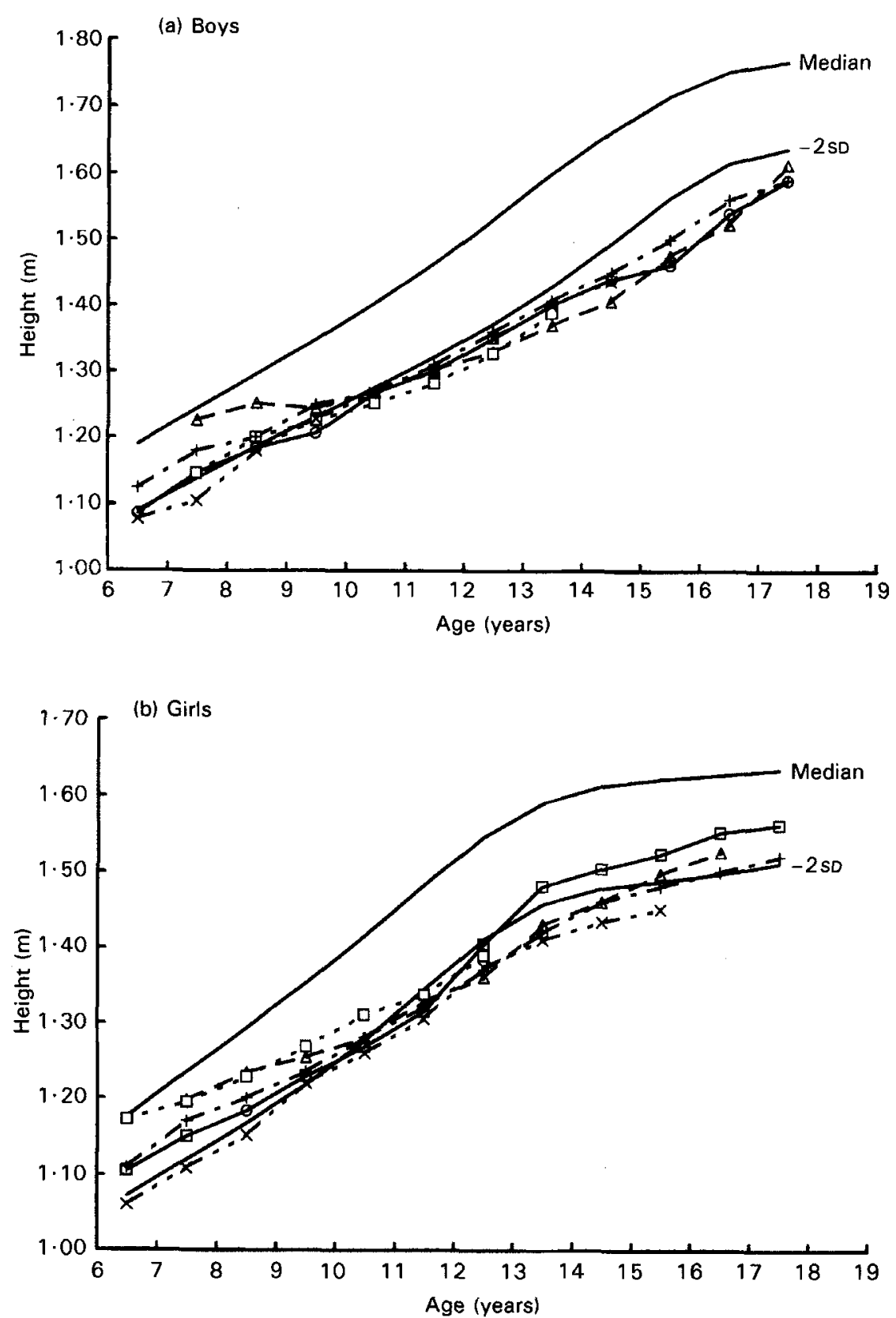

Fig. 1. The mean height of (a) boys and (b) girls in five Partnership for Child Development countries by age with the median and -2 sD of the National Center for Health Statistics reference values (World Health Organization, 1983). (O), Ghana; $(\Delta)$, Tanzania; $(\square)$ Indonesia; $(+)$, Vietnam; (X), India.

moderately stunted and between 15 and $22 \%$ were severely stunted). Significantly more boys were stunted than girls in all samples of children (all $P<0.001$ ) except in Gujarat, India; but only in Ghana and Tanzania were significantly more boys than girls found to be severely stunted (Ghana: RR $2.45,95 \%$ CI $2.02-2.98, P<0.001$; Tanzania: RR $1.55,95 \%$ CI $1.27-1.90)$.

The values for prevalence have not been standardized to reflect the distribution of children by age in schools and may, if one age group is represented disproportionately in the sample studied, lead to a bias in the overall prevalence of stunting. Data on total enrolment by age and sex were only available for Tanzania, which indicated that the prevalence of stunting was reasonably accurately estimated by the sample. Using data on the distribution by age and sex of all primary school children in three districts of Tanga Region in 1994 (Eberstein, 1994), the prevalence of stunting was standardized for age by sex and revealed that stunting among boys was underestimated by $3.3 \%$ and severe stunting by $3.5 \%$; for girls the values were $1.1 \%$ and $1.6 \%$ respectively.

Fig. 4(a) shows the mean values of $z$-scores of heightfor-age for boys by age, and reveals that in all countries there was a trend for $z$-scores of height-for-age to decrease with age, so that older boys were significantly more stunted than younger boys. Fig. 4(b) shows the same data for girls 


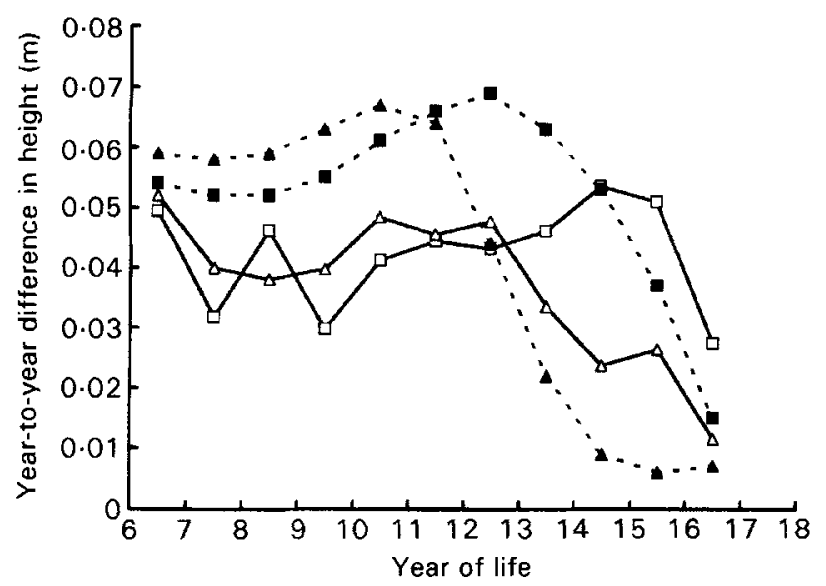

Fig. 2. The year-to-year difference in mean height $(\mathrm{m})$ of boys ( $\square$ ) and girls $(\triangle)$ in Vietnam with, for comparison, the same year-to-year difference in the median height of boys $(\boldsymbol{\square})$ and girls $(\boldsymbol{\Delta})$ taken from the National Center for Health Statistics reference values (World Health Organization, 1983).

and reveals a trend among girls aged between 7 and 12 years similar to that observed among boys of the same age range. However, in three of the four countries for which data were available on adolescent children, older girls showed a significant upturn in mean height-for-age; girls aged 13 years or more in Ghana, Tanzania and Vietnam all showed a trend for mean z-scores of height-for-age to be higher with age, and in these countries the mean z-scores of height-for-age were significantly higher among girls aged 13 years or older than among boys of the same age (all $P<0.001$ ). There were no data for children of the same age range from Indonesia, and among Indian children there were no significant differences in mean $z$-scores of heightfor-age between boys and girls aged 13-15 years.

The apparently better anthropometric status of the youngest children in Tanzania seen in Figs. 1 and 4 is thought to be due to the selection of taller children for enrolment in school. Children are supposed to enrol in primary school at the age of 7 years in Tanzania, but in 1994 in 350 primary schools in three districts of Tanga Region only $12 \%$ of children in class 1 were actually 7 years old and the average age was 9.3 years (PCD, 1997b). Parents in Tanzania have been reported to hold the view that children can be 'too small' to go to school at 7 years of age, while teachers have been reported to discourage parents from enrolling children who are too small or immature (Tanzania Development Research Group, 1993).

\section{Weight-for-age}

Fig. 5 shows (using the same format as Fig. 3) the prevalence of underweight in boys and girls in five PCD countries. The percentage of children of either sex who were underweight varied twofold, between 34 and $62 \%$, and a smaller percentage were severely underweight (2$11 \%$ ) than were severely stunted (Fig. 3). But in all countries and for both categories of underweight, significantly more boys were underweight than girls (all $P<0.0001$, except for severely-underweight children in Tanzania, $P=0.019$ ). In Ghana, boys were about six times more likely than girls to be severely underweight (RR 5.7, $95 \%$ CI $3.7-8.8)$.

Fig. 6(a and $b)$ shows the mean z-scores of weight-forage for boys and girls by age, and reveals a picture similar to that of height-for-age, except that schoolchildren in India are clearly the most underweight and that the upturn in weight-for-age is only apparent for children in Ghana and Tanzania and is not as marked.

\section{Weight-for-height}

Fig. 7 shows the prevalence of wasting and uses the same $Y$-axis scale as Fig. 3 (stunting) and Fig. 5 (underweight) so that the data can be compared more easily. Overall wasting

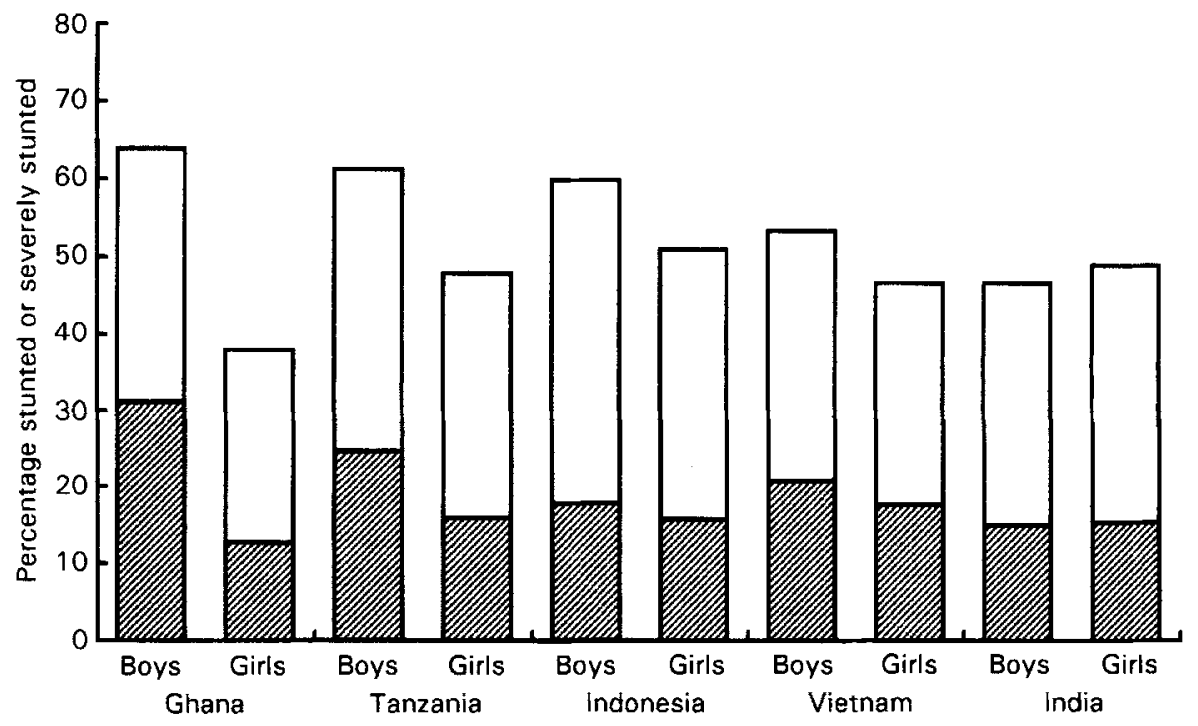

Fig. 3. The percentage of boys and girls who were classified as stunted (z-score of height-for-age $<-2$ SD of National Center for Health Statistics reference values (World Health Organization, 1983); $\mathbb{Z}+\square$ ) in each of five Partnership for Child Development countries and, within that percentage, the percentage who were severely stunted ( $z$-score of height-for-age < $-3 \mathrm{SD}$; 2 ). 

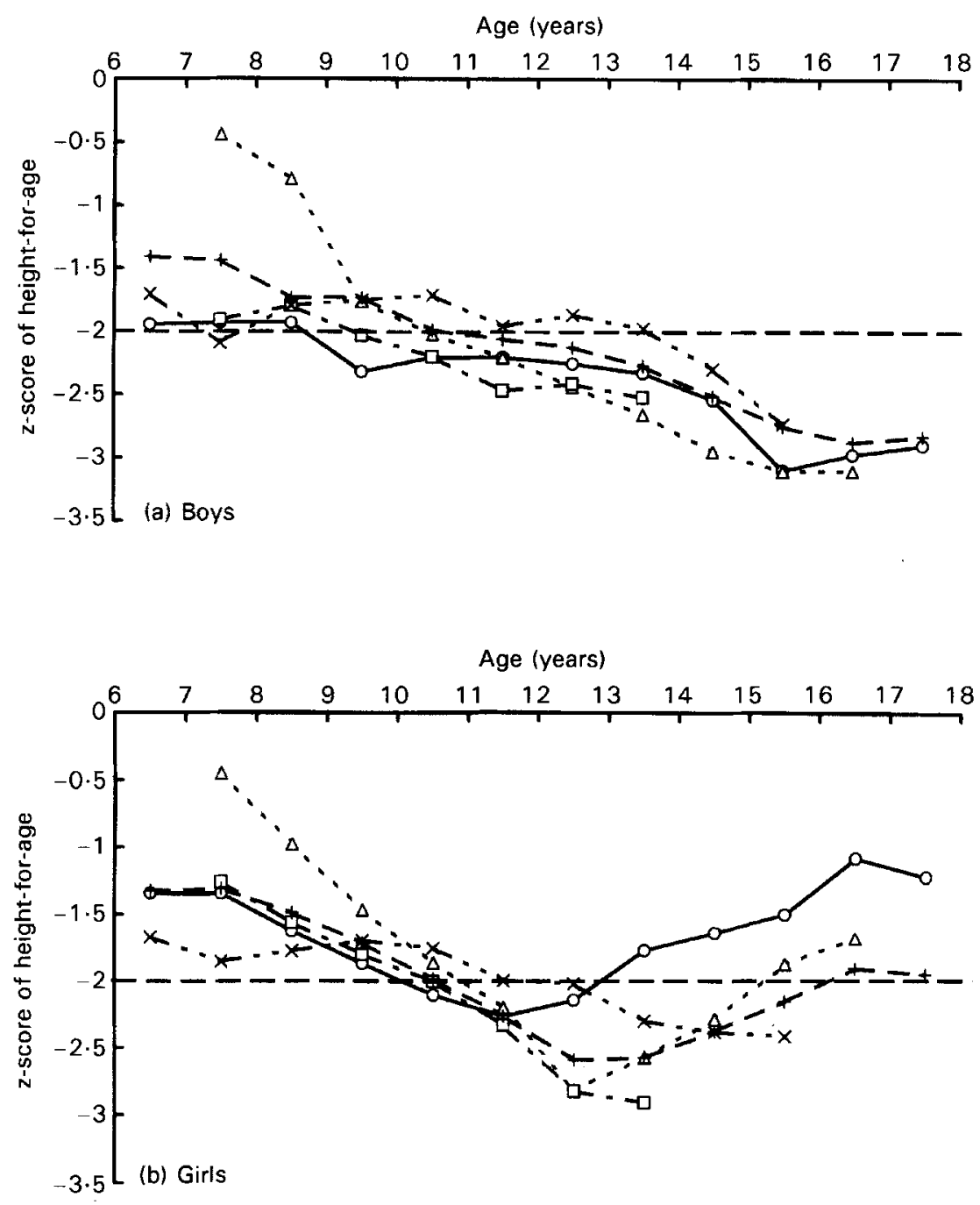

Fig. 4. The mean z-score of height-for-age of (a) boys and (b) girls in five Partnership for Child Development countries by age. (- - ), The cut-off below which children were classified as stunted ( $z$-score of height-for-age $<-2$ SD of National Center for Health Statistics reference values; World Health Organization, 1983). (O), Ghana; $(\Delta)$, Tanzania; $(\square)$, Indonesia; $(+)$, Vietnam; $(X)$, India.

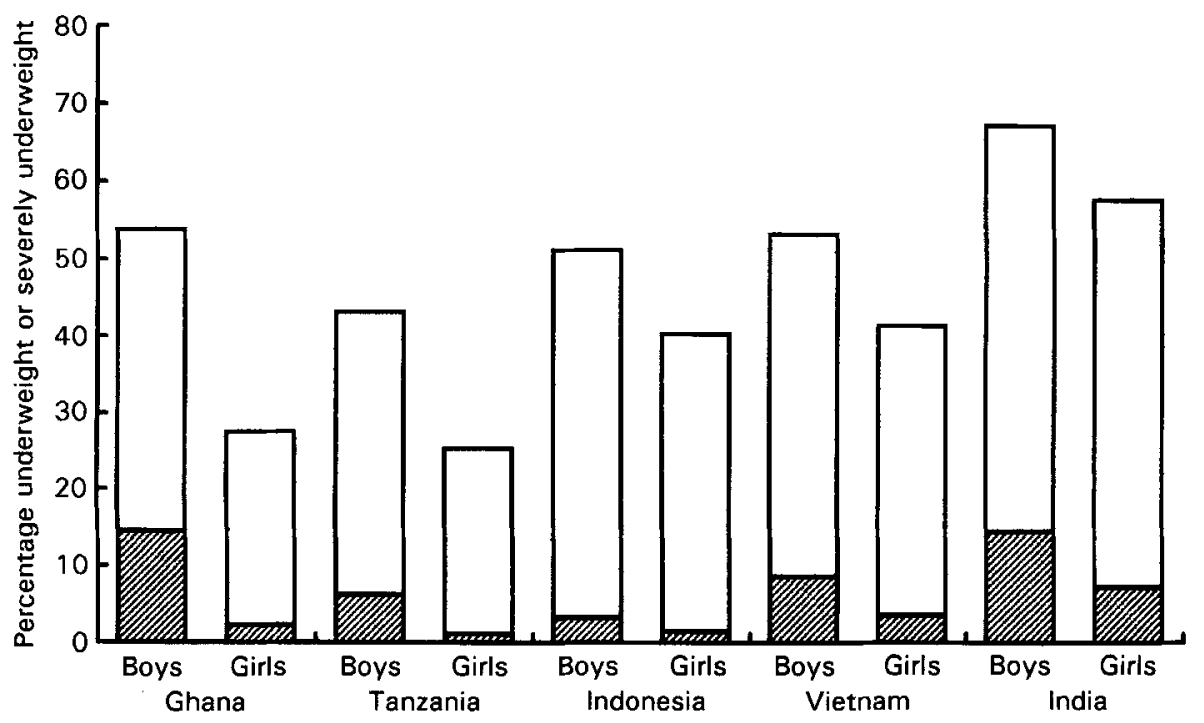

Fig. 5. The percentage of boys and girls who were classified as underweight (z-score of weight-for-age $<-2$ SD of National Center for Health Statistics reference values; World Health Organization, $1983 ;+\square$ ) in each of five Partnership for Child Development countries and, within that percentage, the percentage who were severely underweight (z-score of weight-for-age < $3 \mathrm{SD}$; $\mathbb{Z}$ ). 

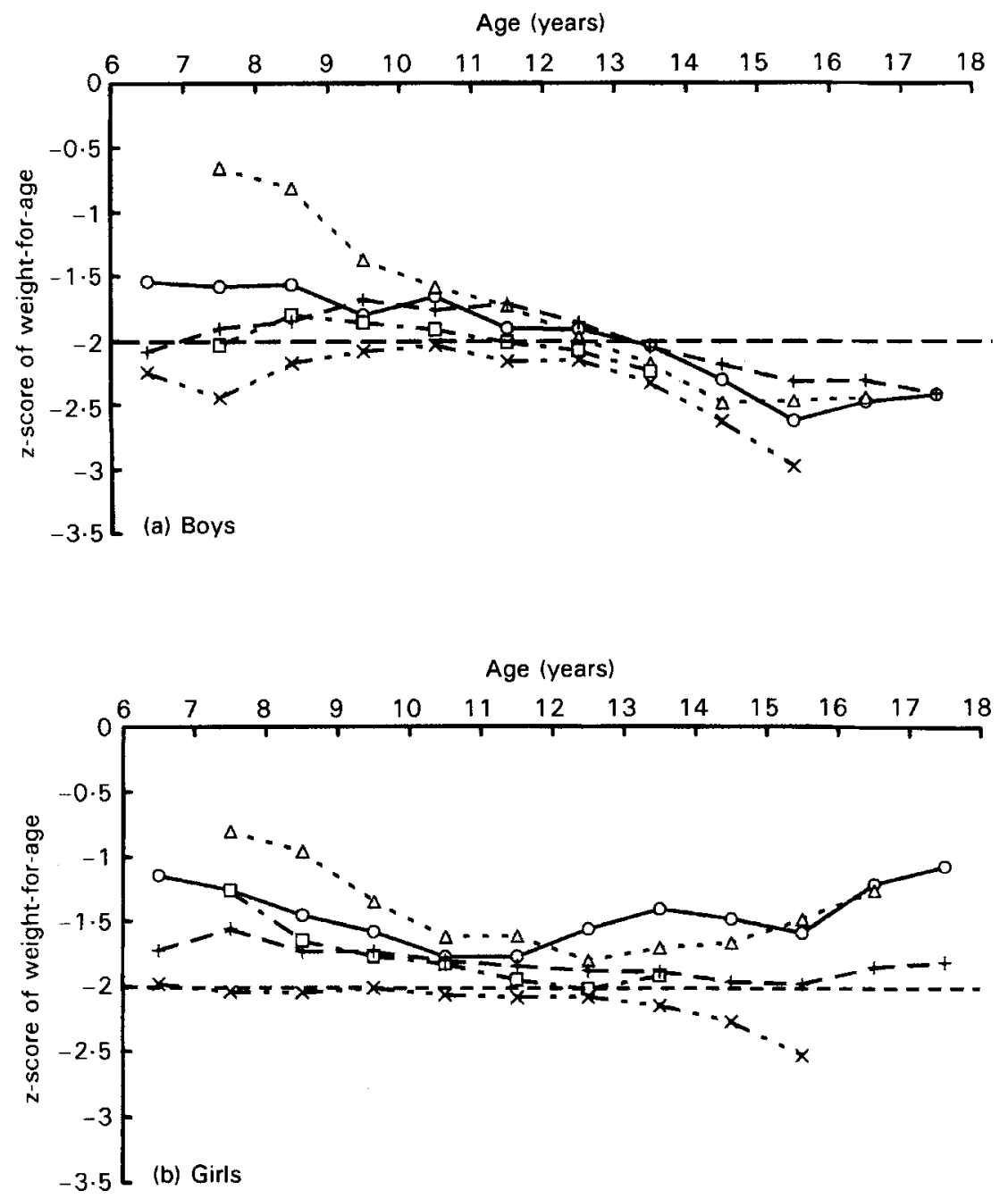

Fig. 6. The mean z-score of weight-for-age of (a) boys and (b) girls in five Partnership for Child Development countries by age. (- - -), The cut-off below which children are classified as underweight ( $z$-score of weight-for-age $<-2$ SD of National Center for Health Statistics reference values; World Health Organization, 1983). (O), Ghana; $(\triangle)$, Tanzania; $(\square)$, Indonesia; $(+)$, Vietnam; $(x)$, India.

was much less common than stunting or underweight in Ghana, Tanzania and Indonesia, but in Vietnam and India, 26 and $31 \%$ of children respectively were classified as wasted. In India, significantly more boys were wasted than girls (RR 1.4, $95 \%$ CI 1.2-1.6, $P<0.001$ ) and in Vietnam about one-third of all wasted children were severely wasted.

\section{$B M I$}

Fig. 8 presents the median of BMI separately for boys and girls by age for each country and shows the median and 5 th percentile of BMI derived from the US First National Health and Nutrition Examination Survey (Hammer et al. 1991).

The BMI of boys in all countries tended to diverge from the First National Health and Nutrition Examination Survey median but, except for Indian boys, remained within the 5 th percentile. The BMI of girls appeared generally to be better than that of boys and tended either to be parallel to the median or converged towards it during adolescence. The BMI of both Indian boys and girls was below the 5 th percentile in all but one age group.

\section{Discussion}

This is one of the largest surveys of anthropometric measurements of rural schoolchildren in developing countries of which we are aware, and while we do not make any claim that the samples of schoolchildren are representative of children in each country, a comparison of the data shows some interesting similarities and trends among children in widely separated countries in West and East Africa, in South and North Asia, and in the Indian subcontinent.

First, schoolchildren were, on average, considerably smaller in height and lighter in weight than the NCHS reference population, and overall $51 \%$ of children were defined as stunted, with $19 \%$ severely stunted, and $48 \%$ were underweight, with $6 \%$ severely underweight. The 


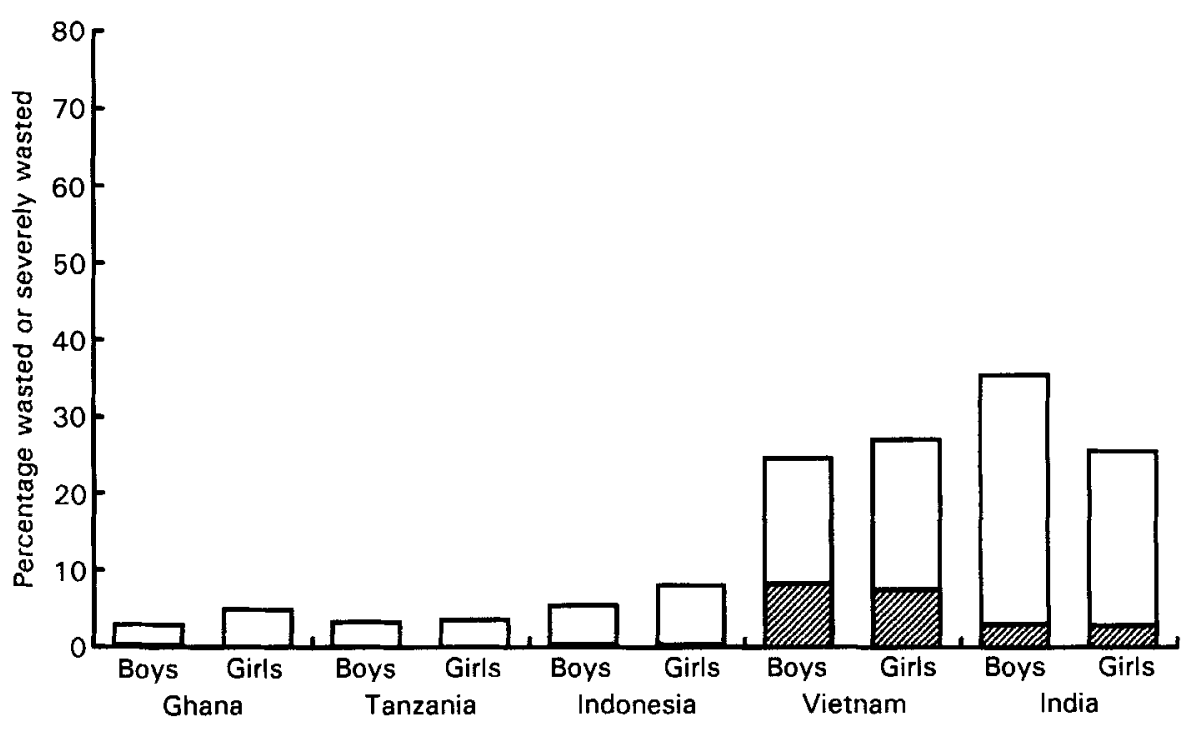

Fig. 7. The percentage of boys aged less than 11.5 years and girls aged less than 10.0 years who were classified as wasted ( $z$-score of weightfor-height $<-2$ so of National Center for Health Statistics reference values; World Health Organization, 1983; $\mathbb{Z}+\square)$ in each of five Partnership for Child Development countries and, within that percentage, the percentage who were severely wasted (z-score of weight-for-height $<-3$ SD; 2 ).

children studied were all enrolled in school and the prevalence of undernutrition may be greater in non-enrolled children. Studies in Ghana (Fentiman \& Hall, 1997) and Tanzania (Beasley, 1995) have shown that non-enrolled children are more undernourished than children enrolled in school; thus, the prevalence of undernutrition presented here may underestimate the prevalence in the whole schoolage population.

Children in Vietnam and India show more evidence of undernutrition and small stature than children in the other three countries. BMI (an index of stature that can be applied to all ages of children, unlike weight-for-height) tends to indicate that children are generally thin as well as being small in comparison with reference populations, and especially so in India. Making such comparisons inevitably raises the question of whether the reference values for height and weight should be viewed as standards, or simply as points of reference for comparative purposes, but there is growing evidence of trends among many populations in Africa and Asia that the attained height of healthy and well nourished children is either not different from NCHS reference values or is converging towards them as a result of secular trends and the elimination of poverty (for review, see Martorell et al. 1988). For example, the height of welloff, urban schoolchildren in Kenya (Stephenson et al. 1983) and Ghana (E Asibey-Berko, personal communication) was not found to be different from NCHS reference values. And a recent study of 25000 Chinese children found an increase in adult height since 1963 of $0.036 \mathrm{~m}$ in boys and $0.027 \mathrm{~m}$ in girls (Leung et al. 1996).

Second, the degree and prevalence of stunting and underweight tended to increase with age. Although there are dangers in interpreting cross-sectional data on growth and indices of growth in terms of longitudinal growth, Fig. 4(a) in particular raises some interesting questions. First, does the decline in mean $\mathrm{z}$-scores of height-for-age of boys reflect the fact that younger boys are less undernourished than older boys have been, or does the increasing deviation from the median of reference values reflect persistent and chronic undernutrition throughout the school-age years? If the first explanation is true, that this is a sign of a secular trend of better nutrition and improved growth, then the same trend seems to have occurred in five very different countries in both Africa and Asia over the last 10 years (the age range covered by the children studied here) and has led to a marked improvement in growth. In Vietnam, for example, the z-score of height-for-age of boys in their 16th year is -1.5 SD lower than that for boys in their 7 th year, a difference which is equivalent in boys aged 16 years to about $0.10 \mathrm{~m}$ in attained height.

An alternative explanation for the apparent decline in mean z-scores of height-for-age is that linear growth, which is known to start to falter after 3 months of age in many developing countries, so that children grow at approximately $80 \%$ of reference gains or less during the first 2 years of life (Waterlow, 1988), may be persistently low throughout the school-age years. The data presented here and other studies undertaken within the Tanzania PCD programme (Beasley, 1995) suggest that growth in height continues to diverge from reference values and that stunting is persistent. This has been confirmed by a recent study of schoolchildren in Zanzibar (Stoltzfus et al. 1997) and the same trend is also seen among school-age children in Papua New Guinea (Norgan, 1995).

Third, boys in most countries tended to be significantly more stunted than girls, and in all countries boys were more underweight than girls. The better height-for-age of older girls in Ghana, Tanzania and Vietnam shown in Fig. 4(b), but not in boys (Fig. 4(a)), is noteworthy. This could be explained by the fact that more girls drop out of school than boys and that those who drop out are more likely to come from poor homes and be undernourished, thereby leaving a better-nourished population of girls still enrolled in school. In Ghana, girls are indeed more likely to drop out of school 

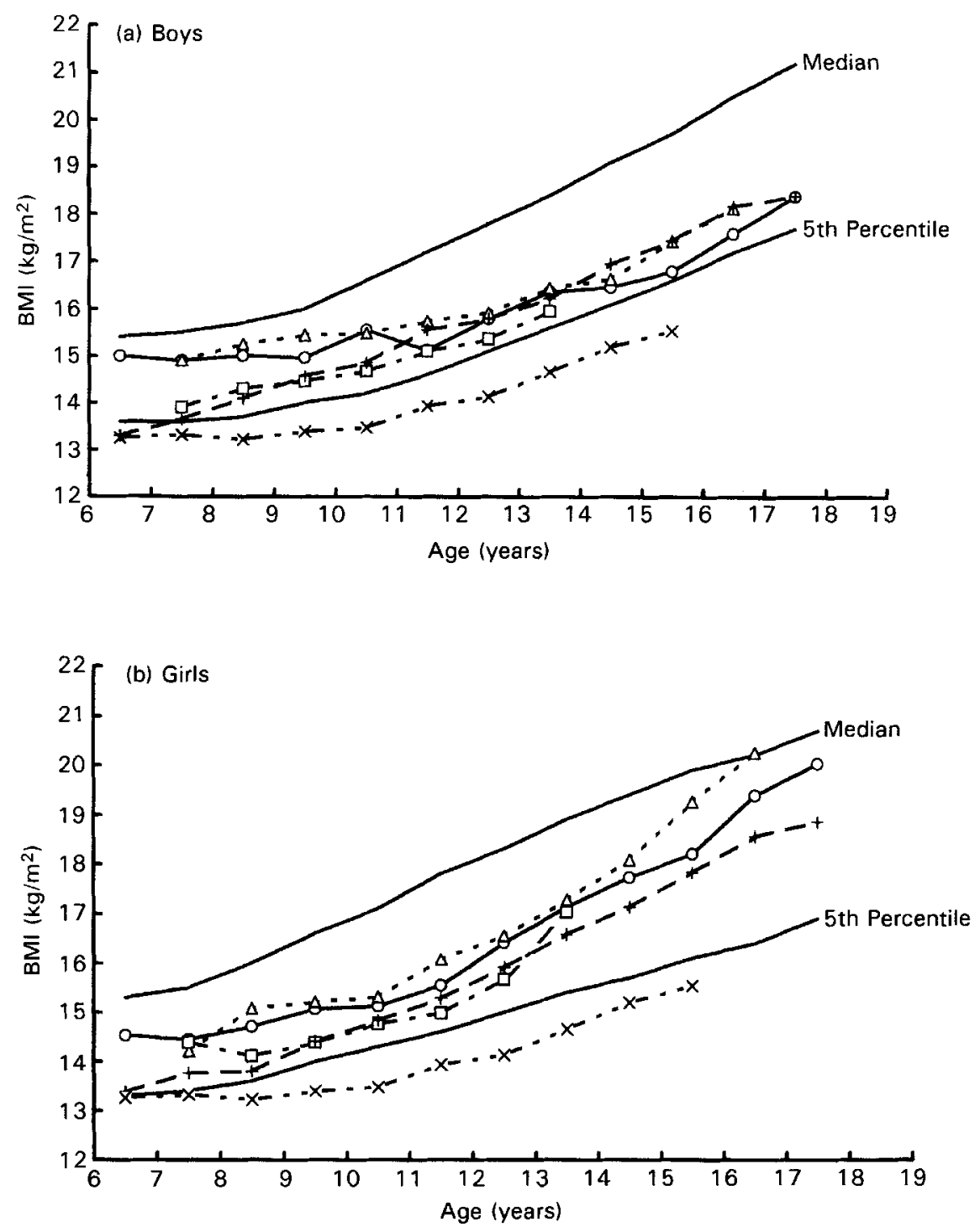

Fig. 8. The mean BMl of (a) boys and (b) girls for schoolchildren in five Partnership for Child Development countries by age with the median and the 5th percentile derived from First National Health and Nutrition Examination Survey data (Hammer et al. 1991). (O), Ghana; $(\triangle)$, Tanzania; $(\square)$, Indonesia; $(+)$, Vietnam; (X), India.

in adolescence than boys or not make the transition to junior secondary school (PCD, 1995), but in Tanzania and Vietnam the sex ratios in the highest class of primary school are not significantly different from 1:1 (Government of Tanzania/United Nations Children's Fund, 1990; PCD, 1997b; Ministry of Education, Vietnam, unpublished results). A second possible explanation for the differences between adolescent girls and boys in Ghana, Tanzania and Vietnam could be that girls are simply better nourished. This is unlikely if, in general, the boys and girls studied come from the same households, and would imply either that girls get more food to eat than boys or that there are significant physiological differences between boys and girls consuming the same diet which result in better growth in girls. It is possible, for example, that girls may be more likely than boys to be involved in food preparation in the household, but whether this would translate into such a marked difference in height gain is uncertain.
Another possible explanation for the difference between boys and girls in these three countries is that the adolescent growth spurt is either delayed in boys or does not occur at all. In girls, the upturn in height (Fig. 1) and height-for-age (Fig. 4(b)) in relation to NCHS values appears to occur at about 13 years of age, later than is typical in well-nourished girls (Tanner, 1978). The presentation in Fig. 2 of year-toyear differences in height of children in Vietnam does not accurately represent growth velocity (for data, see Tanner \& Davies, 1985), but it may indicate patterns in growth. There is no clear spurt in year-to-year changes in height in both boys and girls and there is distinct persistence of height gain into the late teens, particularly among boys, suggesting that linear growth may be prolonged. A study of black children in South Africa found that puberty in poor urban children was both delayed and lasted longer than it did among well-off black children who were, in turn, slightly ahead of European children (Cameron et al. 1993). 
If the upturn shown in Fig. 4(b) in height-for-age observed among girls in Ghana, Tanzania and Vietnam is related to a growth spurt at puberty, then either the upturn in girls in India and in boys in all countries for which there are data occurs at a later age, or it does not occur at all. More data will be needed on adolescents and young adults in PCD countries, particularly in India, to answer questions about the age at which boys and girls stop growing in height. In all countries, data on growth velocity will also help to answer these questions. PCD programmes in Ghana, Tanzania, Indonesia and Vietnam are currently collecting such data.

The conclusions of this analysis are that impaired growth is widespread among schoolchildren in rural Africa and Asia; that growth retardation seems to occur throughout the school-age years; and that boys are significantly more stunted and underweight than girls, perhaps because the adolescent growth spurt is delayed by chronic undernutrition or does not occur at all. The facts that linear growth continues to falter in this age group and that linear growth appears to continue at a relatively high rate beyond the age typically associated with puberty in the face of (or perhaps because of) undernutrition, suggests that school health and nutrition programmes have the potential to bring about catch-up growth through the school-age years.

\section{Acknowledgements}

The Partnership for Child Development is supported by the United Nations Development Programme, the Rockefeller Foundation, the Edna McConnell Clark Foundation, the James S. McDonnell Foundation, the Wellcome Trust, the World Bank, UNICEF, the World Health Organization, and the British Ministry for International Development.

\section{References}

Beasley NMR (1995) A study of parasitic helminth infection and iron deficiency in school age children: population distribution and dynamics of interaction. DPhil Dissertation, University of Oxford.

Cameron N, Grieve CA, Kruger A \& Leschner KF (1993) Secondary sexual development in rural and urban South African black children. Annals of Human Biology 20, 583-593.

Clarke NMA, Grantham-McGregor SM \& Powell C (1991) Nutrition and health predictors of school failure in Jamaican children. Ecology of Food and Nutrition 26, 47-57.

Eberstein T (1994) A Report on the Collection of Primary School Education Statistics in Tanga Region. UKUMTA Report Series Dar es Salaam, Tanzania: Tanzania Partnership for Child Development.

Fentiman A \& Hall A (1997) Factors Influencing School Enrolment and the Health of Children. Accra, Ghana: UNICEF.

Gopaldas T \& Gurjal S (1996) The Pre-Post Impact Evaluation of the Improved Mid-Day-Meal Programme, Gujarat. Baroda, India: Tara Consultancy Services.

Government of Tanzania/United Nations Children's Fund (1990) Women and Children in Tanzania. Dar es Salaam, Tanzania: Government of Tanzania and UNICEF.

Hammer LD, Kraemer C, Wilson DM, Ritter PL \& Dornbusch DM (1991) Standardized percentile curves of body-mass index for children and adolescents. American Journal of Diseases of Children 145, 259-263.
Jamison DT (1986) Child malnutrition and school performance in China. Journal of Development Economics 20, 299-309.

Leung SSF, Lau JTF, Xu YY, Tse LY, Huen KF, Wong GWK, Law WY, Yeung VTF, Yeung WKY \& Leung NK (1996) Secular changes in standing height, sitting height and sexual maturation of Chinese - the Hong Kong growth study, 1993. Annals of Human Biology 23, 297-306.

Martorell R, Mendoza F \& Castillo R (1988) Poverty and stature in children. In Linear Growth Retardation in Less Developed Countries, pp. 57-68 [JC Waterlow, editor]. New York: Raven Press.

Moock PR \& Leslie J (1986) Childhood malnutrition and schooling in the Terai region of Nepal. Journal of Development Economics 20, 33-52.

Nokes C \& Bundy DAP (1994) Does helminth infection affect mental processing and educational achievement? Parasitology Today 10, 14-18.

Norgan NG (1995) Changes in patterns of growth and nutritional anthropometry in two rural modernizing Papua New Guinea communities. Annals of Human Biology 22, 491-513.

Partnership for Child Development (1995) Social, Economic and Cultural Factors Infuencing Enrolment in School by Females in Ghana and the Health of Children in and out of School. Oxford: Partnership for Child Development.

Partnership for Child Development (1997a) Better health, nutrition and education for the school-aged child. Transactions of the Royal Society of Tropical Medicine and Hygiene 91, $1-2$.

Partnership for Child Development (1997b) Age and Gender Patterns in the Tanzanian Primary School: Implications for School-based Health Programmes. Oxford: Partnership for Child Development.

Stephenson LS (1987) Impact of Helminth Infection on Human Nutrition. London: Taylor \& Francis.

Stephenson LS, Latham MC \& Jansen A (1983) A Comparison of Growth Standards: Similarities between NCHS, Harvard, Denver and Privileged African Children and Differences with Kenyan Rural Children. Cornell International Nutrition Monograph Series no. 12. Ithaca, NY: Cornell University.

Stoltzfus RJ, Albonico M, Tielsch JM, Chwaya HM \& Savioli L (1997) Linear growth retardation in Zanzibari school children. Journal of Nutrition 127, 1099-1105.

Sullivan KM \& Gorstein J (1990) Anthro. Software for Calculating Pediatric Anthropometry. Atlanta, GA: CDC and Geneva: WHO.

Tanner JM (1978) Foetus into Man: Physical Growth from Conception to Maturity. London: Open Books.

Tanner JM \& Davies PSW (1985) Clinical longitudinal standards for height and height velocity for North-American children. Journal of Pediatrics 107, 317-329.

Tanzania Development Research Group (1993) Parents' Attitudes and Strategies Towards Education in Rural Tanzania. Dar es Salaam, Tanzania: Tanzania Development Research Group.

Warren KS, Bundy DAP, Anderson RM, Davis AR, Henderson DA, Jamison DT, Prescott N \& Senft A (1993) Helminth infection. In Disease Control Priorities in Developing Countries, pp. 131-160 [DT Jamison, WH Mosely, AR Meashem and JL Bobadilla, editors]. Oxford: Oxford Medical Publications.

Waterlow JC (1988) Observations on the natural history of stunting. In Linear Growth Retardation in Less Developed Countries, pp. 1-12 [JC Waterlow, editor]. New York: Raven Press.

World Bank (1993) World Development Report 1993. Investing in Health. Oxford: Oxford University Press.

World Health Organization (1983) Measuring Change in Nutritional Status. Geneva: WHO. 


\section{Appendix}

Principal investigators for the work reported here are:

Professor Don Bundy

Dr Michael Beasley

Dr Alicia Fentiman

Dr Andrew Hall

Scientific Coordinating Centre for the Partnership for Child Development, Wellcome Trust Centre for the Epidemiology of Infectious Disease, Oxford University, South Parks Road, Oxford OX1 3PS, UK

Dr Sam Adjei

Dr Frank Nyonator

Dr S-T Wen

Ghana Partnership for Child Development, c/o Health Research Unit, PO Box 184, Accra, Ghana

Professor Charles Kihamia

Tanzania Partnership for Child Development (UKUMTA), Ocean Road Hospital, PO Box 9383, Dar es Salaam, Tanzania
Dr Satoto

Dr Hertanto Subagio

Dr Sri Hendratno

Indonesia Partnership for Child Development (Mitra), c/o Research Institute, University of Diponegoro, Semarang, Central Java, Indonesia

Professor Ha Huy Khoi

Dr Le Nguyen Bao Khanh

Dr Do Kim Lien

Dr Nguyen Duy Toan

Vietnam Partnership for Child Development, c/o National Institute for Nutrition, 48 Tang Bat Ho, Hanoi, Vietnam

Professor Tara Gopaldas

Professor Sunder Gujral

India Partnership for Child Development, Tara Consultancy Services, 124/B Varthur Road, Nagavarapalya, Bangalore 560003, India 